\title{
Austenite in transformation-induced plasticity steel subjected to multiple isothermal heat-treatments
}

\author{
Van Tuan Duong ${ }^{\mathrm{a}}$, You Young Song ${ }^{\mathrm{a}}$, Kyong-Su Park ${ }^{\mathrm{b}}$, H. K. D. H. \\ Bhadeshia $^{\mathrm{a}, \mathrm{c}}$, Dong-Woo Suh ${ }^{\mathrm{a}}$ \\ ${ }^{a}$ Graduate Institute of Ferrous Technology, POSTECH, Republic of Korea \\ ${ }^{b}$ Technical Research Laboratories, POSCO, Republic of Korea \\ ${ }^{c}$ Materials Science and Metallurgy, University of Cambridge, UK
}

\begin{abstract}
The thermodynamic limit to the progress of the bainite reaction in steels containing a cementite-inhibitor, often leaves large quantities of thermally or mechanically unstable austenite. Such austenite is not effective in delaying the onset of plastic instabilities during the course of deformation. In such circumstances, it is useful to conduct isothermal transformation at a high temperature where the rate of reaction is relatively rapid, followed by a lower temperature step that permits more bainite to be generated. This in turn increases the stability of the refined austenite, which then transforms gently over a large range of strain during a tensile test. A significant corollary is that the two-step heat treatments are unnecessary in low-carbon steels, where the bainite reaction is able to proceed to a greater extent before reaching the thermodynamic limit. Furthermore, the two-step process can be counter-productive in low carbon steel, because the austenite content is reduced to a level below which it does not enhance the mechanical properties. Other circumstances in which multiple heat treatments are necessary are also discussed.
\end{abstract}

Keywords: austenite stability, transformation-induced plasticity, bainite, multiple heat treatments, mechanism of bainite transformation

Email address: dongwoo1@postech.ac.kr (Dong-Woo Suh) 


\section{Introduction}

Ever since the work of Papadimitriou and Fourlaris [1] on carbide-free bainite it has been known that implementing two stages of isothermal transformation, both below the bainite-start temperature, leads to a refinement of microstructure. The amount of bainite that can form at a given temperature is limited by the $T_{0}$ curve, which represents the locus of points on a temperature versus carbon concentration plot where austenite and ferrite of identical composition have the same free energy. A second step at a lower temperature therefore permits further transformation to bainite, thus reducing the quantity of retained austenite in the final structure. Bainite plates generated at a lower temperature are also finer $[1,2]$ and hence contribute more to strength $[3,4]$. A two-stage process of this kind can be beneficial in reducing the overall transformation time if the reaction at the lower temperature is slow. The internal stresses generated during transformation at the higher temperature can stimulate the kinetics of transformation at a lower temperature [5-7].

Coarse regions of austenite are known to lead to poor toughness and ductility [8-11]. It is reasonable therefore to expect an improvement in the mechanical properties using a two-step heat treatment that allows sufficient time in each stage for the bainite reaction to stop. Using such heat treatments, a large increase in ductility and toughness was achieved in a high carbon steel [12]. Similarly, a significant improvement in the tensile strength, without compromising ductility, has recently been reported for a medium carbon steel subjected to this kind of a two-step isothermal transformation, with the benefits attributed to the refinement of structure [13]. The detailed composition of the steel studied was

$$
\text { Fe-0.3C-1.46Si-1.97Mn-1.5Ni-0.3Cr-0.96Cu-0.25Mo wt\% }
$$

The purpose of the present work was to study the role of two-step transformation into bainite, in steels with a much lower substitutional solute content and two different carbon concentrations, and to assess specifically the role of the retained austenite during the course of deformation. As will be seen later, almost identical properties are possible to achieve with these simpler steels, and it will be shown that the two-step heat treatment does not always lead to improved properties relative to the single isothermal transformation experiment. 


\section{Experimental technique}

The chemical compositions of the alloys, prepared by vacuum induction melting, are listed in Table 1 . The two alloys differ in carbon content and contain $2 \mathrm{wt} \% \mathrm{Mn}$ to suppress allotriomorphic ferrite and $1.5 \mathrm{wt} \% \mathrm{Si}$ to inhibit the formation of cementite during the bainite transformation. After casting, the alloys were heated to $1473 \mathrm{~K}\left(1200^{\circ} \mathrm{C}\right)$ for $2 \mathrm{~h}$ and hot-rolled to $2 \mathrm{~mm}$ thick sheet, with the rolling completed at a temperature above $1173 \mathrm{~K}$ $\left(900^{\circ} \mathrm{C}\right)$, followed by air-cooling to ambient temperature.

Subsequent heat treatments were conducted either using a dilatometer or an infrared heating furnace. Figure 1 illustrates the heat treatment paths; one set of samples was isothermally transformed at a single temperature following austenitisation at $1203 \mathrm{~K}\left(930^{\circ} \mathrm{C}\right)$ for $5 \mathrm{~min}$, which is given in Table 2 . The first isothermal transformation temperature $T_{1}$ was set above the martensite-start temperature $M_{S}$ of the alloy, and the second temperature $T_{2}<T_{1}$ was above the martensite-start temperature $M_{S 2}$ of the enriched austenite remaining following the first isothermal step. The martensite-start temperatures in each case were determined experimentally using dilatometry [14]; an example is illustrated in Figure 2. The temperature $T_{2}$ was set by allowing the transformation at $T_{1}$ to consume approximately $60 \%$ of the austenite, and accounting for the fact that it should be higher than $M_{S 2}$.

The microstructures were examined using light and scanning electron microscopy (SEM) together with electron back-scattered diffraction (EBSD). Specimen for metallographic analysis was prepared using a standard method etched with $2 \%$ nital followed by $10 \%$ sodium metabisulfite solution. For EBSD analysis, the specimens were mechanically polished, followed by electropolishing with $10 \%$ perchloric acid solution and examined using a step size of $0.1 \mu \mathrm{m}$. The austenite fraction was measured with X-ray diffraction using monochromated $\mathrm{Cu} \mathrm{K} \mathrm{K}_{\alpha}$ radiation. The specimens were prepared by mechanical and chemical polishing to remove oxide or deformed layer using 10 $\% \mathrm{HF}+\mathrm{H}_{2} \mathrm{O}_{2}$ solution. Integrated intensities of $(200)_{\alpha},(211)_{\alpha}$, and $(220)_{\gamma}$, $(311)_{\gamma}$ peaks were used for the evaluation of austenite fraction. The carbon concentration in austenite was determined using the following equation of the lattice parameter as a function of composition [15]:

$$
a_{\gamma} / \mathrm{nm}=0.3572+0.00012 w_{\mathrm{Mn}}-0.000157 w_{\mathrm{Si}}+0.00056 w_{\mathrm{Al}}+0.0033 w_{\mathrm{C}}
$$

where $w$ is the weight percent of the solute in the subscript, and consis- 
tent with atom probe observations, the elements other than carbon do not partition even on the finest conceivable scale [16-21].

Tensile testing was conducted at a crosshead speed of $0.625 \mathrm{~mm} \mathrm{~min}^{-1}$, using tensile test specimen according to ASTM specifications, with a parallel length of $32 \mathrm{~mm}$ and a gauge length of $25 \mathrm{~mm}$. Interrupted tensile tests were used to assess the stability of austenite, and the austenite fraction in the uniformly strained region was measured using X-ray diffraction.

\section{Results and Discussion}

\subsection{Microstructures}

Figure 3(a) shows the change of austenite content as a function of $T_{1}$. The retained austenite fraction in alloy A gradually increases with isothermal treatment temperature, while the maximum observed for alloy $\mathrm{B}$ is because a substantial part of the austenite remaining untransformed at $T_{1}=723 \mathrm{~K}$ $\left(450^{\circ} \mathrm{C}\right)$ decomposes into martensite on cooling as shown in Figure 3(b). Corresponding optical micrographs are shown in Figure 4, where the white features represent the austenite and dark ones are bainite or martensite. In alloy $\mathrm{A}$, most of microstructure consists of bainitic ferrite and small islands of retained austenite. It is noted that there are relatively larger grains which seem to be a mixture of retained austenite and martensite at $T_{1}=723 \mathrm{~K}$ $\left(450^{\circ} \mathrm{C}\right)$. It is thought to form by partial martensitic transformation of coarse austenite grains during final cooling. Even with this partial transformation, the austenite fraction is increased at $T_{1}=723 \mathrm{~K}\left(450^{\circ} \mathrm{C}\right)$ in Figure 3 (a), possibly due to the higher population of small austenite islands. In alloy $\mathrm{B}$, comparable to the XRD result, the quantity of austenite appears to be larger at $T_{1}=673 \mathrm{~K}\left(400^{\circ} \mathrm{C}\right)$ than $723 \mathrm{~K}\left(450^{\circ} \mathrm{C}\right)$ in alloy $\mathrm{B}$. The microstructre subjected to isothermal treatment at $723 \mathrm{~K}\left(450^{\circ} \mathrm{C}\right)$ indicates that coarse austenite grains mostly transforms into martensite on cooling. Figure 5 shows the carbon concentration in austenite in final microstructure. Most of carbon concentration in austenite agree well with $T_{0}^{\prime}$, which defines the locus of points where austenite and ferrite containing (400 $\mathrm{J} \mathrm{mol}^{-1}$ of stored energy) of the same chemical composition have identical free energies. The $T_{0}^{\prime}$ curve is a thermodynamic limit in the sense that the bainite reaction cannot proceed once the carbon concentration of the austenite exceeds that given by the limit [22]. The bainite reaction therefore halts well before the austenite reaches 
its equilibrium or paraequilibrium composition, thus leaving coarse regions of untransformed austenite. One option to refine the coarse austenite is to promote further transformation by reducing the transformation temperature, which is the basis for the two-step heat-treatment.

Figure 6 shows the austenite content following the two-step process. For comparison, the austenite fraction after single isothermal treatment is also presented. When the isothermal temperature is below $673 \mathrm{~K}\left(400^{\circ} \mathrm{C}\right)$, subsequent isothermal treatment at a lower temperature decreases the austenite fraction in most conditions. This is because the second heat treatment allows further formation of bainitic ferrite by increasing the critical carbon concentration in austenite over which the formation of bainitic ferrite is not possible.

The exception is the data in alloy $\mathrm{B}$ where $T_{1}=723 \mathrm{~K}\left(450^{\circ} \mathrm{C}\right)$ and $T_{2}=$ $623 \mathrm{~K}\left(350^{\circ} \mathrm{C}\right)$, which leads to a larger fraction of austenite than for the single treatment with $T_{1}=723 \mathrm{~K}\left(450^{\circ} \mathrm{C}\right)$. As explained previously, the austenite that is left untransformed following the first step is unstable to martensitic transformation, so the fraction retained in the singular process is dramatically reduced. On the other hand, cooling from $T_{1}$ to $T_{2}=623 \mathrm{~K}\left(350^{\circ} \mathrm{C}\right)$ results in further bainitic transformation and stabilises the austenite.

Figure 7 shows the microstructures resulting from the two-step processing; as expected, the fraction of austenite $\left(V_{\gamma}\right)$ is seen to be less than that associated with the single isothermal transformation (Figure 4). Furthermore, the regions of retained austenite are clearly refined, although the effect is less obvious for the lower carbon alloy A where transformation can in any case generate more bainite since less carbon is partitioned into the austenite per quantity of bainite that forms. Thus, the amount of retained austenite in alloy $\mathrm{A}$ for single step with $T_{1}=673 \mathrm{~K}\left(400^{\circ} \mathrm{C}\right)$ is approximately $12 \%$ and this austenite is present already in a refined state as shown in Figure 4 (a). Therefore, any decrease induced by additional transformation at a lower temperature is rather small, from $12 \%$ to $7.5 \%$, leading only to a limited refinement of the austenite islands.

\subsection{Mechanical properties}

Figure 8 shows the tensile test results for alloys A and B. The ultimate tensile strength obtained is greater using the two-step treatment with the exception of alloy B transformed at $T_{1}=723 \mathrm{~K}\left(450^{\circ} \mathrm{C}\right)$, where the residual 
austenite is not stable on cooling to room temperature with a single isothermal treatment.

The trend for elongation depends on the average carbon concentration of the alloy. In alloy $\mathrm{A}$ with $w_{\mathrm{C}}=0.24 \mathrm{wt} \%$, the two-step treatment worsens the ductility with the opposite effect observed in alloy B which contains $0.41 \mathrm{wt} \%$ carbon. In alloy $\mathrm{B}$, an increase in elongation from $5 \%$ to $30 \%$ is observed for the single and two-step heat treatments for which $T_{1}=723 \mathrm{~K}\left(450^{\circ} \mathrm{C}\right)$.

A parameter often used to assess strength and elongation together is the product of these two parameters, plotted in Figure 8c. It is clear the the lower carbon alloy A does not improve when given a two-step heat-treatment.

\subsection{Influence of two-step isothermal heat treatment}

The changes in microstructure due to the additional bainite forming at the lower temeperature can be summarised as follows:

- fragmentation of the coarse austenite regions;

- enrichment of austenite with additional carbon, thus enhancing its stability;

- change in austenite fraction, the sign of the change depending on the stability of the austenite produced in the first higher temperature step of transformation.

It is possible that the deterioration in the performance of alloy A when subjected to the two-step treatment may be related to the decrease in the fraction of retained austenite below the quantity needed to sustain work hardening via the TRIP effect, over larger values of elongation. The usual commercially available low-carbon TRIP-assisted steels contain 10-15\% of retained austenite [11, 23-26]. Since the austenite fractions in alloy A after single isothermal treatment at $673 \mathrm{~K}\left(400^{\circ} \mathrm{C}\right)$ or $723 \mathrm{~K}\left(450^{\circ} \mathrm{C}\right)$ fall into that range, any further transformation at a lower temperature will reduce the austenite content to less than $10 \%$, thereby compromising the elongation [27, 28]. Indeed, the additional bainitic ferrite generated at $T_{2}$ increases the tensile strength by $100-150 \mathrm{MPa}$, but this is not the essential cause of the loss in ductility because the product of strength and elongation is systematically reduced with the two-step treatment. Furthermore, as shown in Figures 4a and 
7a, the austenite already has fine grain structure even with single isothermal treatment of alloy A, so the multi-isothermal treatment is difficult to have an advantage regarding to the refinement of austenite grains.

In alloy $\mathrm{B}$, it is clear that the two-step treatment significantly improves the mechanical properties when $T_{1}>673 \mathrm{~K}\left(400^{\circ} \mathrm{C}\right)$. Its austenite content is a substantial $30 \%$ after the single isothermal treatment at $673 \mathrm{~K}\left(400^{\circ} \mathrm{C}\right)$, and $18 \%$ and $24 \%$ using two steps at $673 \mathrm{~K}-623 \mathrm{~K}\left(400^{\circ} \mathrm{C}-350^{\circ} \mathrm{C}\right)$ and $723 \mathrm{~K}-$ $623 \mathrm{~K}\left(450^{\circ} \mathrm{C}-350^{\circ} \mathrm{C}\right)$, respectively. It follows that the multiple isothermal treatment is a promising way to control the characteristics of austenite in the high carbon alloy to make full use of TRIP effect from refined austenite. For a quantitative analysis of the characteristics of austenite, the grain size and carbon concentration in retained austenite was compared for three cases illustrated in Figure 9. From the EBSD images, the grain size of austenite was changed little in the range $2.5-1.9 \mu \mathrm{m}$. The corresponding carbon concentrations are shown in Table 4. As expected, additional transformation at $T_{2}$ enhances the carbon concentration from $0.78 \mathrm{wt} \%$ to 0.98 or $0.88 \mathrm{wt} \%$. In Table 3 , the consequent reduction in the $M_{S}$ temperatures both from the size and composition effects are listed. The carbon effect was calculated using [29]:

$$
M_{S}\left({ }^{\circ} \mathrm{C}\right)=539-423 \mathrm{w}_{\mathrm{C}}-30.4 \mathrm{w}_{\mathrm{Mn}}-17.7 \mathrm{w}_{\mathrm{Ni}}-12.1 \mathrm{w}_{\mathrm{Cr}}-11 \mathrm{w}_{\mathrm{Si}}-7 \mathrm{w}_{\mathrm{Mo}}
$$

and the size effect using [30]:

$$
\Delta M_{S}=\frac{1}{b} \ln \left[\frac{1}{a \bar{V}_{\gamma}}\left\{\exp \left(-\frac{\ln (1-f)}{m}\right)-1\right\}+1\right]
$$

Here, $\bar{V}_{\gamma}$ is the average volume of the austenite regions, $f$ is first detectable martensite fraction and $m$ is aspect ratio of the martensite plate, set to be 0.01 and 0.05 , respectively. $a$ and $b$ are constants of $1.57 \times 10^{-21} \mu \mathrm{m}^{3}$ and 0.253 respectively. Table 3 shows the enhancement of austenite stability obtained using the multiple isothermal treatment in this study, primarily from the further enrichment of carbon.

It is emphasised that conventional TRIP-assisted steels contain allotriomorphic ferrite as the major phase, which results in the enrichment of the residual austenite prior to the formation of bainite at a lower temperature. This kind of enrichment is lacking in the present work where allotriomorphic ferrite is absent. Furthermore, there is now considerable evidence that unlike 
allotriomorphic ferrite, bainitic ferrite retains much more carbon in solution and at defects associated with the displacive transformation mechanism [1618, 31-36]. As a consequence, for equal volume fractions of allotriomorphic and bainitic ferrite, the former must lead to a greater enrichment of austenite. This means that the two-step heat treatment is very useful in cases where the structure does not contain allotriomorphic ferrite, but is predominantly bainitic.

Figure 10 illustrates the stability of the retained austenite during a tensile test, confirming that the two-step treatment renders greater stability to the austenite in alloy $\mathrm{B}$, so that the transformation-induced plasticity can be sustained over a larger plastic strain.

\section{Conclusions}

The influence of a two-step heat treatment on the characteristics of retained austenite in bainitic TRIP steel has been studied. The following conclusions emerge:

1. There is no doubt that when isothermal transformation results in a large quantity of retained austenite, further transformation at a lower temperature is beneficial both from a microstructural and tensile properties point of view. This is because the additional formation of bainite at the second transformation temperature helps refine the austenite and further enrich it with carbon, thus enhancing its mechanical stability.

2. There are circumstances where the first isothermal transformation temperature leads to a quantity of austenite that is so large that a significant fraction then decomposes by martensitic transformation on cooling. Such a scenario benefits enormously by a second lower-temperature stage of isothermal transformation since additional bainitic ferrite is generated in order to reduce the possibility of martensitic transformation on cooling from the bainite transformation temperature.

3. In relatively low carbon alloys that leave little austenite untransformed during isothermal transformation, there is little to be gained by introducing a further step. This is because the austenite is already in a refined state with just a single step of transformation, and reducing the meagre austenite content further leads to a deterioration in the tensile ductility. 
4. Two-step treatments of the kind described here are likely to be advantageous where the major phase is baninitic ferrite. This is because bainitic ferrite retains a considerable excess of carbon and hence is less effective in enriching the austenite at comparable volume fractions and thus second isothermal transformation at lower temperature will contribute to the carbon enrichment into austenite, which is essential in improving the mechanical properties of TRIP-assisted steels.

Finally, it is worth mentioning that imaginative multiple step heat treatments, in the context of bainite, have been reported in the past, where unlike the present work, the initial temperature $T_{1}$ is less than the second stage at $T_{2}>T_{1}[37-39]$. This leads to a substantial improvement in the toughness of the steel or cast iron, by a mechanism which is said to involve the homogenisation of the austenite. Raising the temperature of the second stage does not of course lead to the formation of additional bainite unless insufficient time is available at $T_{1}$ for the carbon concentration of the austenite to be much less than given by the $T_{0}^{\prime}$ curve.

It is also possible that instead of using discrete steps of isothermal transformation, the steel could be cooled continuously at a rate slow enough to permit the $T_{0}^{\prime}$ condition to be satisfied at each temperature. Whether such a treatment is practical remains to be seen, but would be interesting to attempt from a scientific point of view.

Acknowledgements: The authors are grateful to POSCO for support through Steel Innovation Programme, and to the World Class University Programme of the National Research Foundation of Korea, Ministry of Education, Science and Technology, project number R32-2008-000-10147.

[1] G. Papadimitriu, G. Fourlaris: J. de Phys. IV 7 (1997) C5 131-136.

[2] S. B. Singh, H. K. D. H. Bhadeshia: Mater. Sci. Eng. A 245 (1998) $72-79$.

[3] F. B. Pickering: Physical Metallurgy and the Design of Steels: Applied Science Publishers, Essex, U. K., 1978.

[4] K. Zhu, O. Bouaziz, C. Oberbillig, M. Huang: Mater. Sci. Eng. A 527 (2010) 6614-6619. 
[5] R. H. Goodenow, R. H. Barkalow, R. F. Hehemann: Bainite transformations in hypoeutectoid steels: in: Physical properties of martensite and bainite, special report 93: Iron and Steel Institute, London, 1969: pp. $135-141$.

[6] S. H. Lee, J. Y. Kang, H. N. Han, K. H. Oh, H. C. lee, D. W. Suh, S. J. Kim: ISIJ Inter. 45 (2005) 1271-1219.

[7] H.-G. Lambers, D. Canadinc, H. J. Maier: Mater. Sci. Eng. A 541 (2012) $73-80$.

[8] H. K. D. H. Bhadeshia, D. V. Edmonds: Met. Sci. 17 (1983) 411-419.

[9] J. M. Jang, S. J. Kim, N. H. Kang, K. M. Cho, D. W. Suh: Met. Mater. Inter. 15 (2009) 969-916.

[10] L. Rancel, M. Gomez, d. I. G. S. F. Medina a: Mater. Sci. Eng. A 530 (2011) 21-27.

[11] G. Gao, H. Zhang, Z. Tan, W. Liu, B. Bai: Mater. Sci. Eng. A 559 (2013) 165-169.

[12] K. Hase, C. Garcia-Mateo, H. K. D. H. Bhadeshia: Mater. Sci. Eng. A A438-440 (2006) 145-148.

[13] X. L. Wang, K. M. Wu, F. Hu, L. Yu, X. L. Wan: Scripta Mater. 74 (2014) 56-59.

[14] H.-S. Yang, H. K. D. H. Bhadeshia: Mater. Sci. Tech. 23 (2007) 556-560.

[15] E. M. Bellhouse, J. R. McDermid: Metall. Mater. Trans. A 41A (2010) 1460-1473.

[16] H. K. D. H. Bhadeshia, A. R. Waugh: Acta Metall. 30 (1982) 775-784.

[17] I. Stark, G. D. W. Smith, H. K. D. H. Bhadeshia: The element distribution associated with the incomplete reaction phenomenon in steels: an atom probe study: in: G. E. Lorimer (Ed.), Phase Transformations '87: Institute of Metals, London, U.K., 1988: pp. 211-215.

[18] I. Stark, G. D. W. Smith, H. K. D. H. Bhadeshia: Metall. Trans. A 21 (1990) 837-844. 
[19] B. Josefsson, H.-O. Andrén: J. de Phys. Colloque 49 (1988) C6-293 C6-298.

[20] B. Josefsson, H. O. Andrén: Microstructure and thermodynamic behaviour of a Cr-Mo submerged arc weld metal in the as-welded state: in: S. A. David, J. M. Vitek (Eds.), Recent Trends in Welding Science and Technology (TWR'89): ASM International, Metals Park, Ohio, USA, 1989: pp. 243-247.

[21] F. G. Caballero, M. K. Miller, C. Garcia-Mateo: Mater. Sci. Tech. 26 (2010) 889-898.

[22] H. K. D. H. Bhadeshia: Bainite in Steels, 2nd edition: Institute of Materials, London, U.K., 2001.

[23] P. J. Jacques: Curr. Opi. in Sol. Sta. and Mater. Sci. 8 (2004) 259-265.

[24] B. C. DeCooman: Curr. Opi. in Sol. Sta. and Mater. Sci. 8 (2004) 285303.

[25] G. Haidemenopoulos, A. Kermanidis, C. Malliaros, H. Dickert, P. Kucharzyk, W. Bleck: Mater. Sci. Eng. A 573 (2013) 7-11.

[26] R. Blondé, E. Jimenez-Melero, L. Zhao, N. Schell, E. Brüke, S. van der Zwaag, N. H. van Dijk: Mater. Sci. Eng. A 594 (2014) 125-134.

[27] H. K. D. H. Bhadeshia: Proc. of the Roy. Soc. of Lonon A 466 (2010) $3-18$.

[28] C. Garcia-Mateo, F. G. Caballero, T. Sourmail, M. Kuntz, J. Cornide, V. Smanio, E. Elvira: Mater. Sci. Eng. A 549 (2012) 185-192.

[29] K. W. Andrews: J. of the Iron and Steel Ins. 203 (1965) 721-727.

[30] H. S. Yang, H. K. D. H. Bhadeshia: Scripta Mater. 60 (2009) 493-495.

[31] H. K. D. H. Bhadeshia, A. R. Waugh: An atom-probe study of bainite: in: H. I. Aaronson, D. E. Laughlin, R. F. Sekerka, C. M. Wayman (Eds.), Solid-Solid Phase Transformations: TMS-AIME, Warrendale, Pennsylvania, USA, 1982: pp. 993-998. 
[32] M. Peet, S. S. Babu, M. K. Miller, H. K. D. H. Bhadeshia: Scripta Mater. 50 (2004) 1277-1281.

[33] F. G. Caballero, M. K. Miller, S. S. Babu, C. Garcia-Mateo: Acta Mater. 55 (2007) 381-390.

[34] C. Garcia-Mateo, M. Peet, F. G. Caballero, H. K. D. H. Bhadeshia: Mater. Sci. Tech. 20 (2004) 814-818.

[35] F. G. Caballero, M. K. Miller, A. J. Clarke, C. Garcia-Mateo: Scripta Mater. 63 (2010) 442-445.

[36] I. B. Timokhina, X. Y. Xiong, H. Beladi, S. Mukherjee, P. D. Hodgson: Mater. Sci. Tech. 27 (2011) 739-741.

[37] S. K. Putatunda, J. Yang: Mater. Sci. Forum 426-432 (2003) 913-918.

[38] J. Yang, S. K. Putatunda: Mater. Design 25 (2004) 219-230.

[39] S. K. Putatunda, A. Deokar, G. Bingi: Mater. Sci. Forum 638-642 (2010) 3453-3458. 
Table 1: Chemical compositions (wt\%) and Ae3 temperatures of investigated alloys.

\begin{tabular}{ccccccc}
\hline Alloy & $\mathrm{C}$ & $\mathrm{Si}$ & $\mathrm{Mn}$ & $\mathrm{Al}$ & $\mathrm{P}$ & $\mathrm{Ae} 3(\mathrm{~K})$ \\
\hline $\mathrm{A}$ & 0.24 & 1.53 & 2.0 & 0.03 & 0.01 & 1099 \\
$\mathrm{~B}$ & 0.41 & 1.50 & 2.0 & 0.03 & 0.01 & 1057 \\
\hline
\end{tabular}
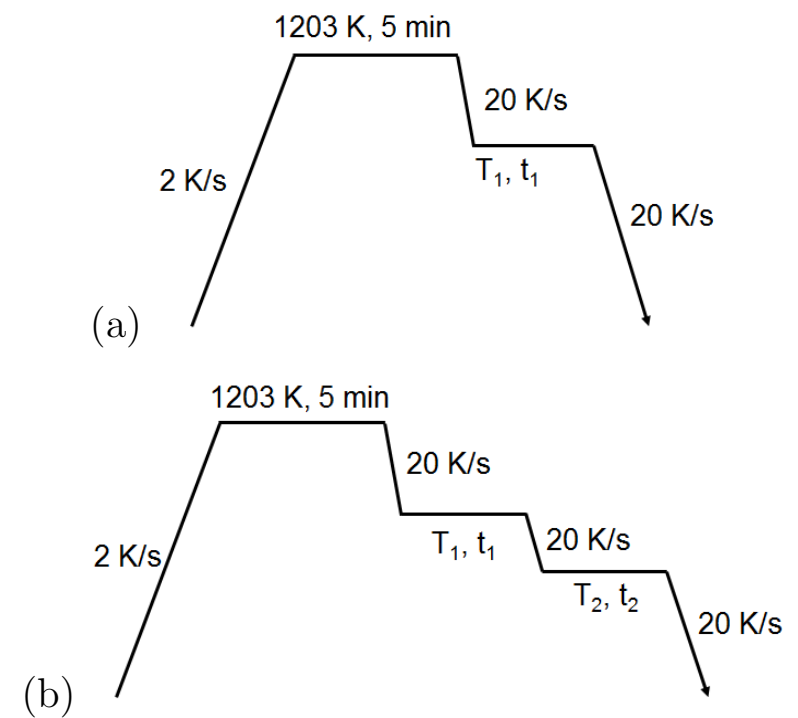

Figure 1: Heat treatment path of (a) single isothermal treatment and (b) multi-isothermal treatment. 
Table 2: Single isothermal heat treatments conducted at the temperature $T_{1}$ for time $t_{1}$. The second set of isothermal transformation parameters are $T_{2}$ and $t_{2}$ respectively. $M_{S 2}$ represents the martensite-start temperature of the austenite remaining following the first isothermal heat treatment.

\begin{tabular}{cccccccc}
\hline Alloy & & $M_{S} / \mathrm{K}$ & $T_{1} / \mathrm{K}$ & $t_{1} / \min$ & $M_{S 2} / \mathrm{K}$ & $T_{2} / \mathrm{K}$ & $t_{2} / \min$ \\
\hline A & A11 & 616 & 623 & 10 & & & \\
& A12 & $"$ & 673 & 10 & & & \\
& A13 & $"$ & 723 & 30 & & & \\
B & B11 & 543 & 573 & 30 & & & \\
& B12 & $"$ & 623 & 30 & & & \\
& B13 & $"$ & 673 & 30 & & & \\
& B14 & $"$ & 723 & 30 & & & \\
A & A21 & 616 & 623 & 0.5 & 587 & 593 & 5 \\
& A22 & $"$ & 673 & 1 & 600 & 623 & 5 \\
& A23 & $"$ & 723 & 1 & 605 & 623 & 5 \\
B & B21 & 543 & 573 & 10 & 473 & 523 & 30 \\
& B22 & $"$ & 623 & 10 & 488 & 523 & 60 \\
& B23 & $"$ & 673 & 10 & 511 & 623 & 60 \\
& B24 & $"$ & 723 & 10 & 513 & 623 & 120 \\
\hline
\end{tabular}

Table 3: Change of $M_{S}$ temperature by multi-isothermal treatment of alloy B.

\begin{tabular}{lcc}
\hline & $673+623 \mathrm{~K}$ & $723+623 \mathrm{~K}$ \\
\hline$\Delta M_{S}$ by grain refinement $(\mathrm{K})$ & -3.2 & -1.0 \\
$\Delta M_{S}$ by C enrichment $(\mathrm{K})$ & -84.6 & -42.3 \\
\hline
\end{tabular}

Table 4: Carbon concentration in austenite after isothermal heat treatment of alloy B.

\begin{tabular}{cccc}
\hline & $673 \mathrm{~K}$ & $673+623 \mathrm{~K}$ & $723+623 \mathrm{~K}$ \\
\hline carbon in austenite $(\mathrm{wt} \%)$ & 0.78 & 0.98 & 0.88 \\
\hline
\end{tabular}




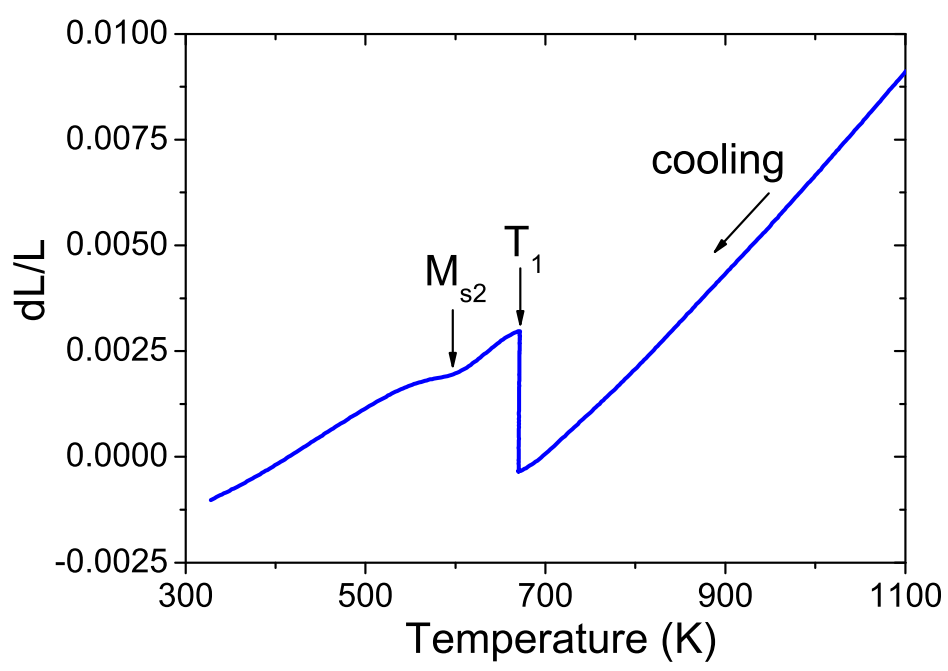

Figure 2: Dilatometric curve for determination of $M_{S 2}$ temperature. 


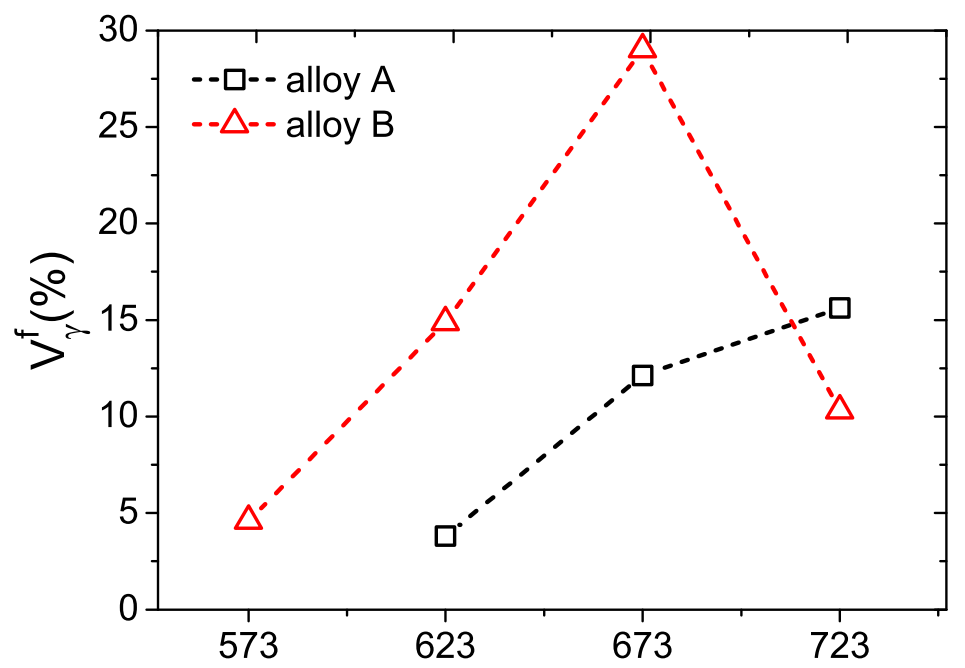

(a)

Isothermal treatment temperature $(\mathrm{K})$

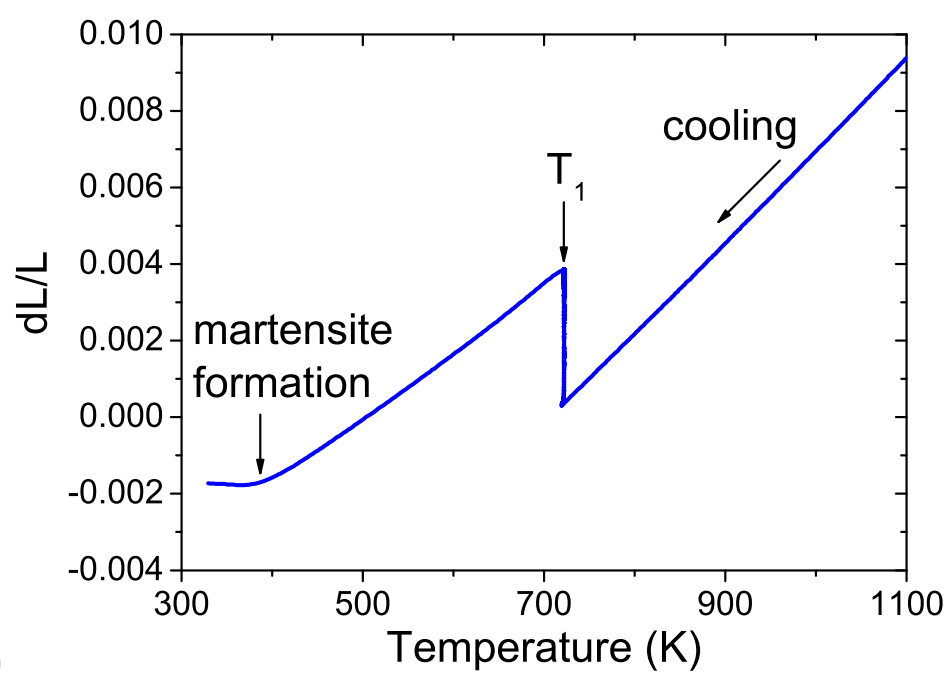

Figure 3: (a) Austenite fraction after single isothermal heat treatment and (b) dilatation curves indicating the formation of martensite in alloy B subjected to single isothermal treatment at $723 \mathrm{~K}\left(450^{\circ} \mathrm{C}\right)$. 

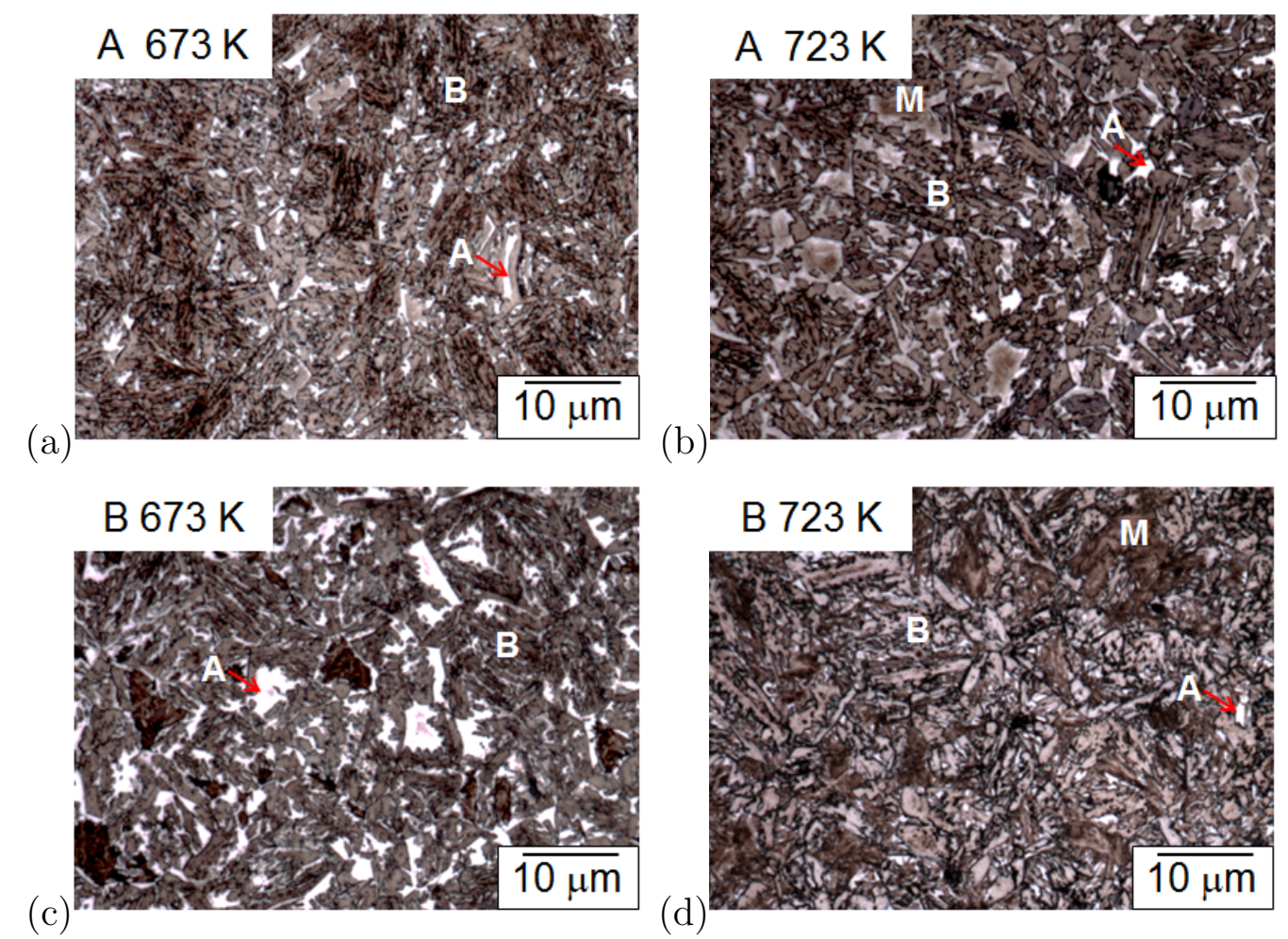

Figure 4: Optical micrographs of alloy A subjected to isothermal treatment at (a) $673 \mathrm{~K}$ $\left(400^{\circ} \mathrm{C}\right)$, (b) $723 \mathrm{~K}\left(450^{\circ} \mathrm{C}\right)$, and alloy B at $(\mathrm{c}) 673 \mathrm{~K}\left(400^{\circ} \mathrm{C}\right)$, (d) $723 \mathrm{~K}\left(450^{\circ} \mathrm{C}\right) . \mathrm{A}, \mathrm{B}$ and $\mathrm{M}$ denote the retained austenite, bainitic ferrite and martensite, respectively 


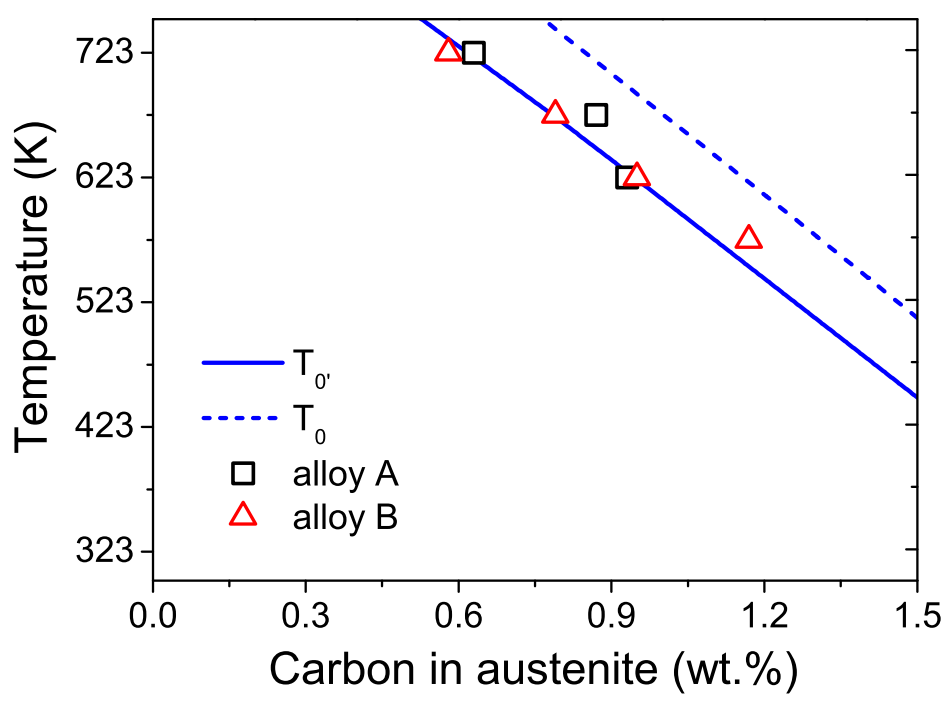

Figure 5: Carbon concentration in austenite compared with $T_{0}^{\prime}$ line. The data are for the single isothermal transformation experiment.

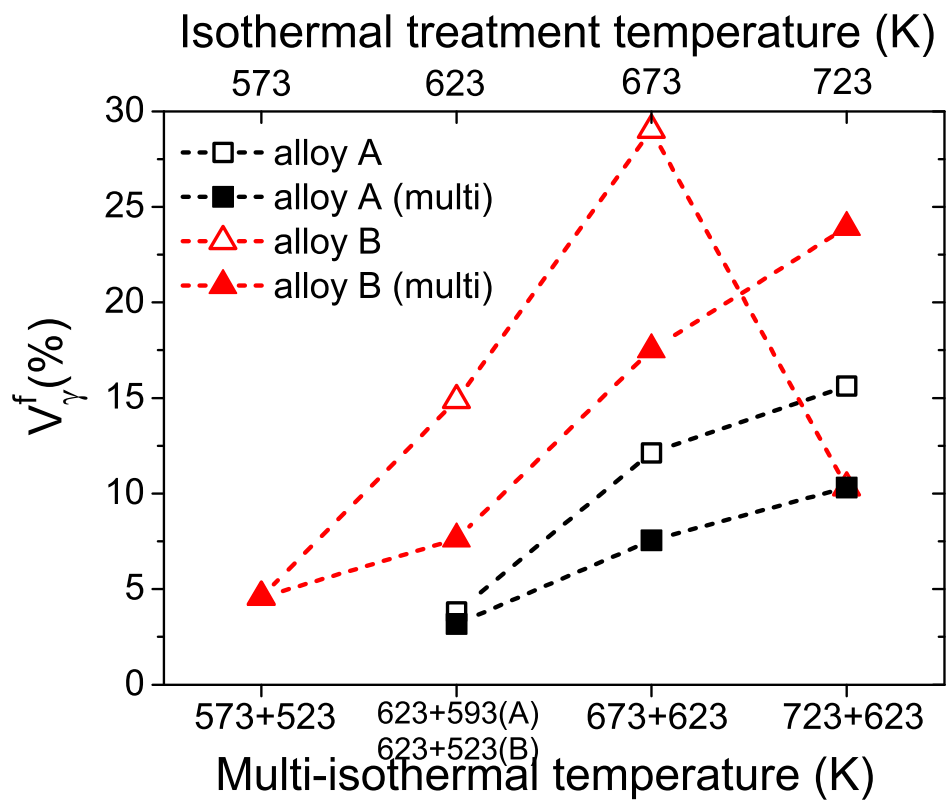

Figure 6: Quantity of austenite after the two-step heat treatment. The labels on the lower horizontal axis indicate $T_{1}-T_{2}$. 

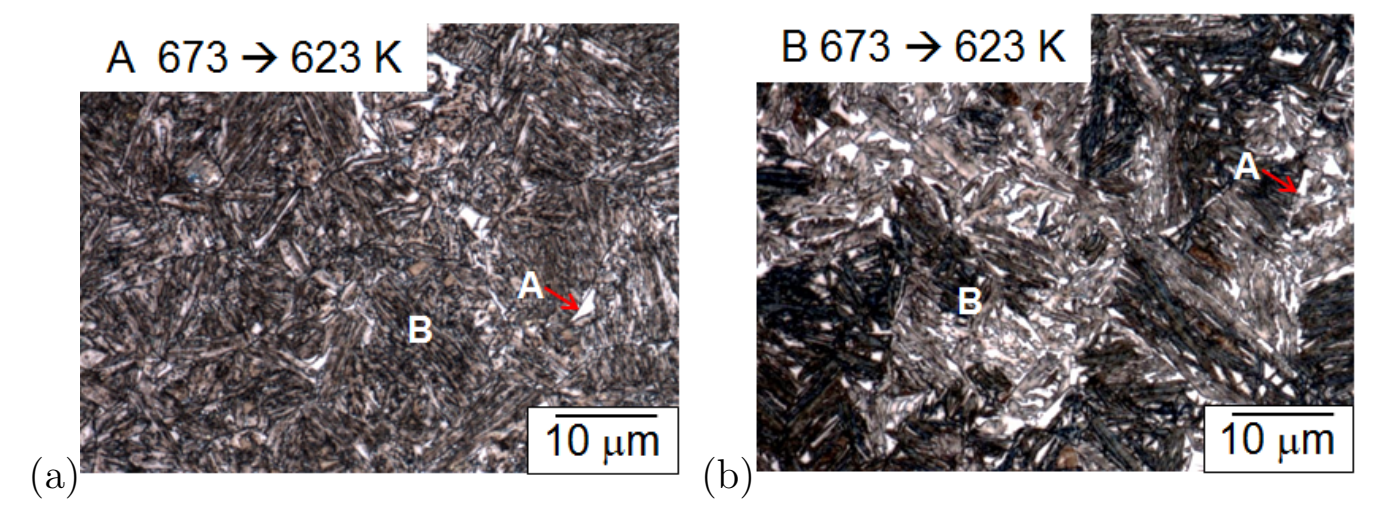

Figure 7: Optical micrographs of alloy A subjected to multi-isothermal treatment at (a) $673 \mathrm{~K}+623 \mathrm{~K}\left(400^{\circ} \mathrm{C}+350^{\circ} \mathrm{C}\right)$ and alloy B at (b) $673 \mathrm{~K}+623 \mathrm{~K}\left(400^{\circ} \mathrm{C}+350^{\circ} \mathrm{C}\right)$. A and $\mathrm{B}$ denote the retained austenite and bainitic ferrite, respectively 


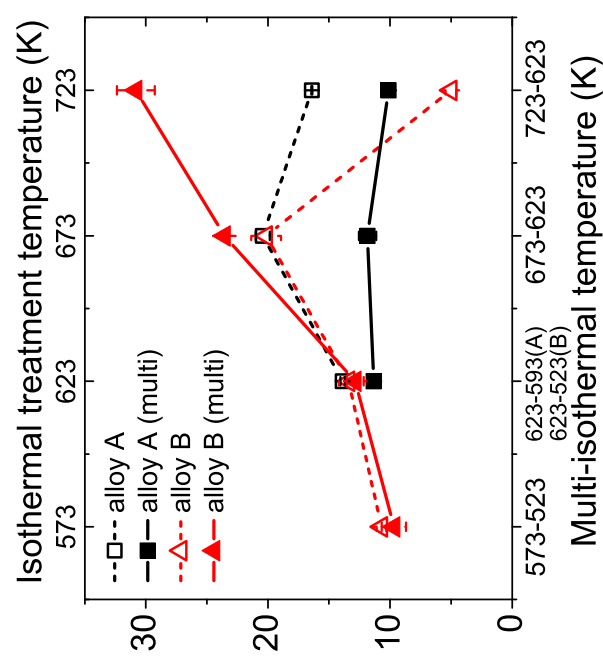

(\%) uo!̣e6uolヨ

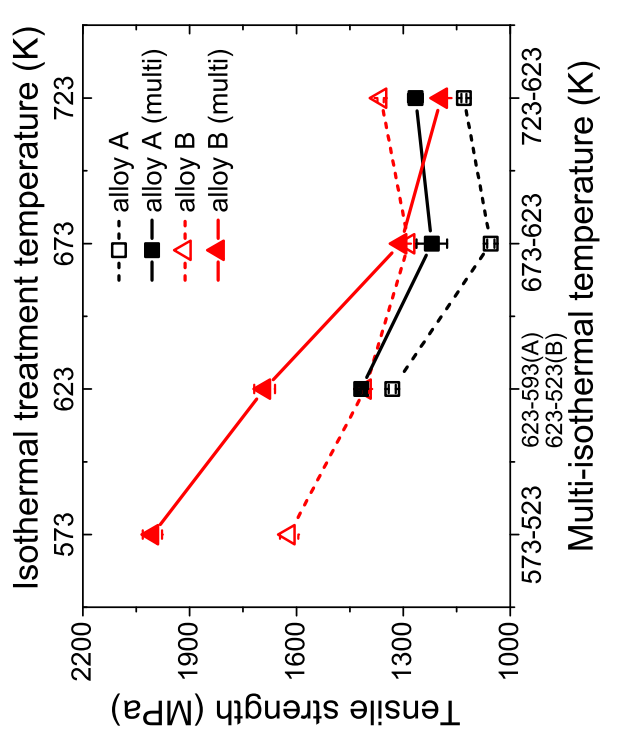

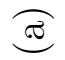

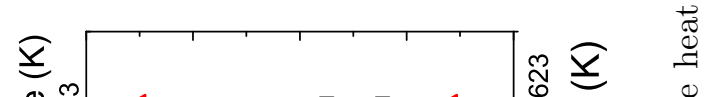

至

¿

Е

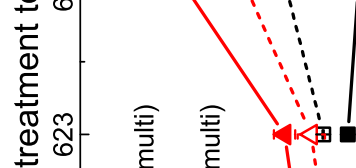

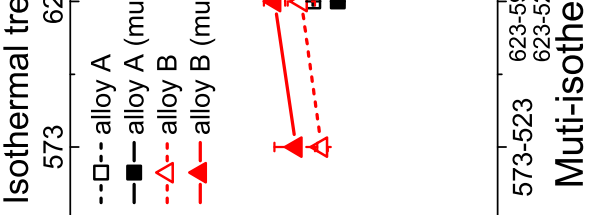

$\sum$

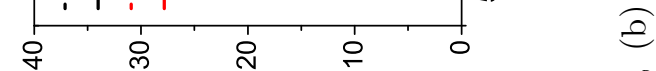

(\%еdつ) әэuеjeq ןеग!uецәәW

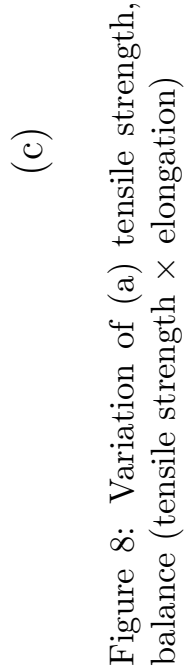



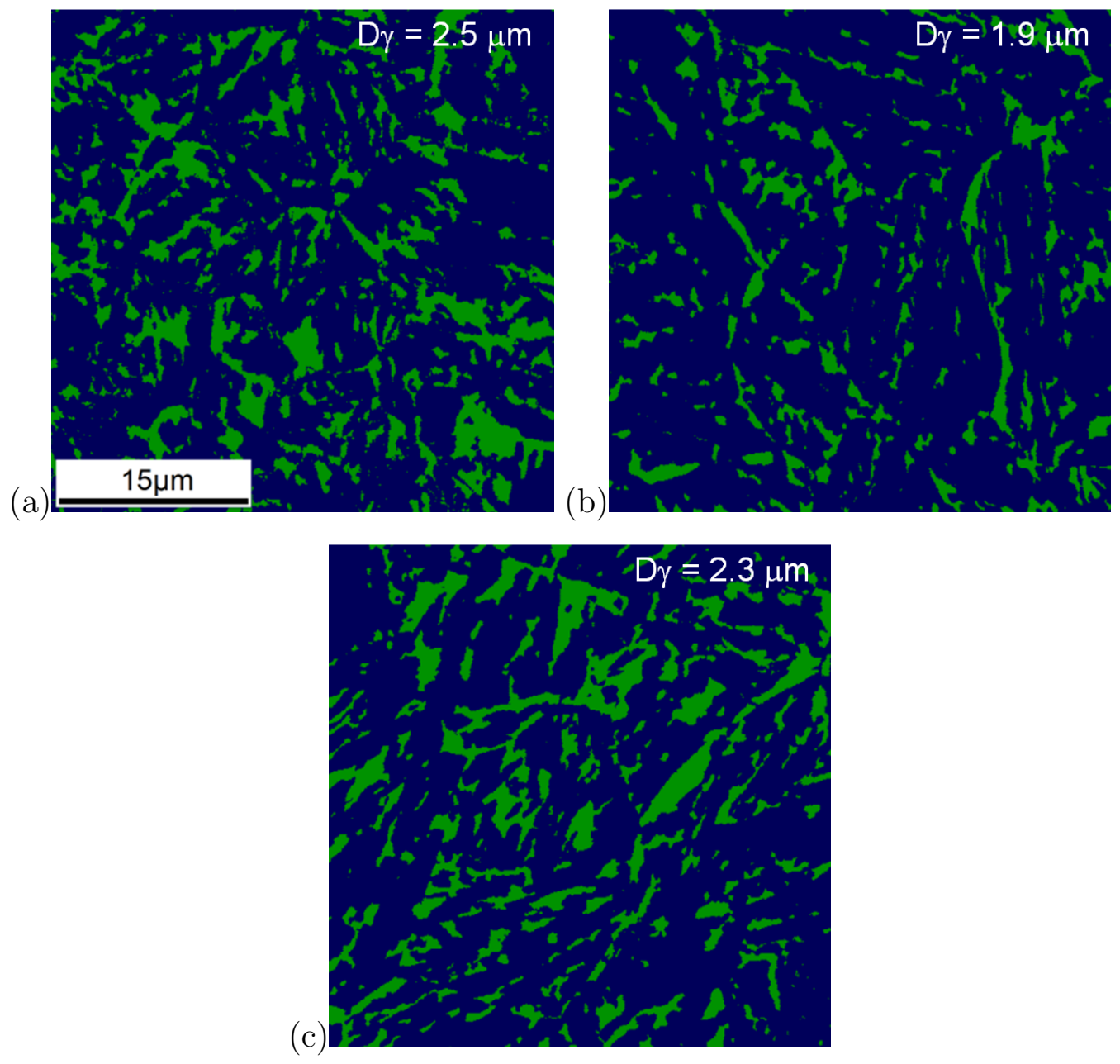

Figure 9: EBSD phase mapping (Green: FCC, Blue: BCC) of alloy B subjected to (a) single isothermal treatment at $673 \mathrm{~K}\left(400^{\circ} \mathrm{C}\right)$, (b) multi-isothermal treatment at $673 \mathrm{~K}+$ $623 \mathrm{~K}\left(400^{\circ} \mathrm{C}+350^{\circ} \mathrm{C}\right)$, and $(\mathrm{c})$ at $723 \mathrm{~K}+623 \mathrm{~K}\left(450^{\circ} \mathrm{C}+350^{\circ} \mathrm{C}\right)$. 


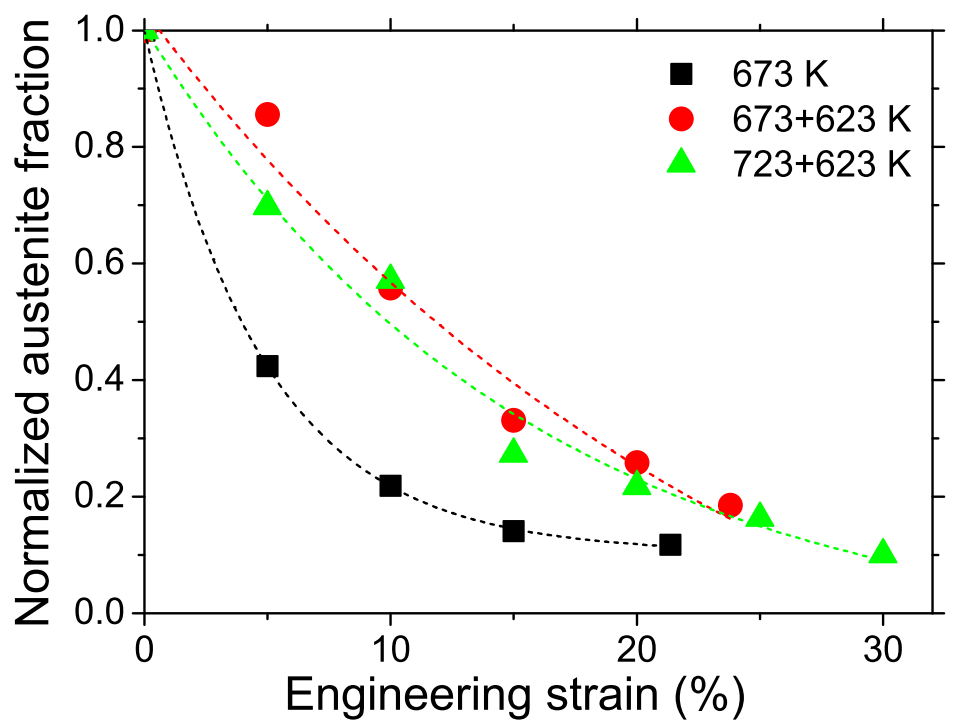

Figure 10: Change of normalised austenite fraction in alloy B as a function of tensile strain. 